\title{
Embodiment and Desire in Browsing Online Pornography
}

\author{
Patrick Keilty \\ University of California, Los Angeles \\ GSEIS Building, Box 951520 \\ Los Angeles, CA 90095 \\ +1 310-953-1727 \\ pkeilty@gmail.com
}

\begin{abstract}
The purpose of this essay is to explore why Spink, Ozmutlu, \& Lorence (2004) found that browsing online pornography requires more time and effort than general searches online. Recent information-seeking behavior research concerning online pornography neglects to examine sexuality or desire as factors influencing this particular information activity. As such, I rely on Lacan's theory of desire, Freud's theory of cathexis, and existential phenomenology, a philosophical method that emphasizes an interpretation of perception and bodily activity, in order to examine the way our embodied relations with the technological apparatus of the computer effect the time and effort of browsing online pornography. In the process, I offer an explanation of subjective analysis as a new mode of description for understanding certain aspects of information activity.
\end{abstract}

\section{Categories and Subject Descriptors}

H.1.2 [Models and Principles] - User/Machine Systems - human factors.

\section{General Terms}

Human Factors, Theory.

\section{Keywords}

Theory, information seeking, browsing, subjectivity, sexuality, pornography.

\section{INTRODUCTION}

The purpose of this essay is to explore why Spink, Ozmutlu, \& Lorence [1] found that browsing online pornography requires more time and effort than general searches online. Recent information-seeking behavior research concerning online pornography neglects to examine sexuality or desire as factors influencing this particular information activity. As such, I rely on Lacan's theory of desire, Freud's theory of cathexis, and existential phenomenology, a philosophical method that emphasizes an interpretation of perception and bodily activity, in order to examine the way our embodied relations with the technological apparatus of the computer effect the time and effort of browsing online pornography. In the process, I offer an explanation of subjective analysis as new modes of description for understanding certain aspects of information activity.

Copyright is held by the author/owner(s).

iConference 2012, February 7-10, 2012, Toronto, ON, Canada ACM 978-1-4503-0782-6/12/02
This essay addresses the concern, as described by Cronin \& Davenport [2], that pornography has been undertheorized and unacknowledged within information studies, despite its prevalence online. Spink, Ozmultlu, \& Lorence [3], too, highlight the "need to develop more detailed models of sexual information seeking and searching." This essay also addresses the need, as identified by Kari \& Hartel [4], to address the pleasurable within information studies, with particular regard to theoretical development and subjective analysis.

Briefly, it is important to note the political and ethical issues associated with pornography, particularly those articulated during the feminist pornography debates of the 1980s. In questioning the fundamental power relations within sex, anti-pornography feminists, such as Andrea Dworkin [5] and Catharine Mackinnon [6], argued that the pornography industry exploits women and is complicit in violence against women in its production, dissemination, and consumption. They believe that pornography actualizes or enacts the real conditions of women's subordination. Others, such as Diana Russell [7], argued that there exists a causal relation between heterosexual pornography and rape. Focusing on sexism rather than obscenity, Dworkin and Mackinnon worked on a campaign that aimed to shield women from assumed harms that stemmed from violent sexual fantasies in heterosexual pornography publications, such as Hustler, by passing ordinances designed to restrict the production, distribution, and consumption of such material.

Other feminists, such as Linda Williams, Drucilla Cornell, and Lara Kipnis dispute Dworkin and Mackinnon's understanding of pornography. They claim that pornography inhabits a realm of representation. If we attend closely to the representational qualities of pornography, Cornell argues [8], it becomes possible to imagine that its graphic erotic content produces, not a literal reality, but a wholesale myth. Williams [9] argues that pornographic films, rather than displaying a sexual reality, frequently strive to represent erotic acts that are by definition impossible to visualize. In doing so, Williams encourages us to think twice about what might be the precise appeal of pornography to male heterosexual consumers. Likewise, Kipnis [10] argues that pornography is intensely and relentlessly about us; it involves the roots of our culture and the deepest corners of the self.

For my part, I have little interest in revisiting those debates in this essay or in imagining what they mean for, say, nonheteronormative pornography, which largely goes unacknowledged in the binary logic of anti-pornography and antianti-pornography. However, I assume throughout this essay that a sexual revolution has taken place over the past half century and that the intense proliferation of and access to pornography occasioned by the Internet is one of its most important and least 
studied effects. In this way, I am talking as much about a revolution in media as I am about individual sexual practices that surround it. This is not to argue that the Internet allows for a triumphant march toward unfettered sexual freedom. Instead, as we shall see, I show only that the Internet has reconstituted our way of being sexual.

I truly wish I could dwell on the ethics and politics of pornography longer, to fully explicate the complicated social and cultural issues that surround it, particularly online pornography, but space limitations allow me to sketch out only the most basic outlines of these issues, and as a result, I have been obliged to omit some of the most fruitful cultural discussions about pornography.

\section{EMBODIMENT AND ONLINE PORNOGRAPHY}

Despite its prevalence within our culture, few studies have been done within information seeking regarding our engagements with and activity around online pornography. Only two major publications attempt to examine the phenomenon from the perspective of information seeking: Spink, Koricich, Jansen \& Cole and Spink, Ozmutlu \& Lorence [11]. Perhaps pornography has been considered too crude to invite much investigation. The catchall phrase "sexual information," which describes pornography in both studies, ${ }^{i}$ is perhaps an example of the way in which scholars attempt (somewhat defensively, I think) to put the sensuous and embodied realm of pornography into objective, detached, and ambiguous terms. The phrase veils potentially uncomfortable research behind dispassionate terminology.

In a more telling example, Spink, Koricich, Jansen \& Cole [12] view our engagements with and activity around online pornography as a serendipitous discovery of "information the user finds while seeking satisfaction of other physiological, affective, and cognitive needs." The authors acknowledge the embodied aspects of pornography (physiological, affective, and cognitive), but only to the extent that these embodied aspects lead to a discovery of "data/ information that will facilitate [users'] adaption and survival" [13]. Through evolutionary psychology, Spink, Koricich, Jansen and Cole explain the desire behind our engagements with and activity around pornography. "The seeking of sexual information on the Internet and elsewhere," they write [14], "may occur not only for the fundamental human purpose of mating and propagation of the species, but also for the diverse information behavior mechanisms concerned with adaption and survival." Thus, according to Spink, Koricich, Jansen and Cole, our encounters with pornography are only ostensibly "nonpurposeful and non-attentive" [15]; instead, in their analysis, the activity serves the higher purpose of sexual reproduction leading to human adaption and survival.

Part of their assumption is that evolutionary concepts of adaption and survival are purposeful or teleological in a way that the sensual aspects of pornography are not. Yet, as cultural critics of evolutionary ideas have shown, evolution is not teleological because it does not end, and it is not purposeful, from an existential standpoint, because it is unclear precisely why we adapt and survive [16]. Furthermore, as I will later show, browsing pornography online, like other pleasurable activities discussed within information-seeking studies, is in fact nonteleological and ultimately non-purposeful (despite an ostensible goal). Its value derives from the pleasure of the "search" itself, and not necessarily from some higher goal or purpose.
Spink, Koricich, Jansen \& Cole's analysis of our activity around pornography privileges an evolutionary need for information over our embodied experiences. In doing so, they imply that our somatic experiences are not valuable in themselves but, curiously, only when they serve a higher utilitarian and productive purpose. Couching the "higher" purpose of pornography through drastically scientific terminology ("mating and propagation of the species," "adaption and survival," [17], Spink, Koricich, Jansen, and Cole rhetorically arrogate the authority of evolutionary science in order to lend a sense of objectivity and detachment to a potentially prurient discussion. Furthermore, they evacuate sexual reproduction of its cultural context and exclude the sexual desires of non-reproductive and queer bodies. By making sexual reproduction the paradigm of sexual desire, Spink, Koricich, Jansen and Cole render non-heteroreproductive bodies derivative of heterosexuality. As such, they privilege heteronormative romantic love and kinship.

Spink, Koricich, Jansen \& Cole and Spink, Ozmutlu \& Lorence rely on behaviorist and scientific modes of description that suppress the body in our engagements with pornography. Yet viewers of pornography do not wish to be exempt from sensual being in browsing pornography online. The pornographic experience is meaningful to many viewers precisely because of their bodies. To the extent that it attempts to arouse sexual feelings, pornography functions in and through a direct visceral appeal to the body. Despite that browsing online pornography is importantly corporal, Spink, Koricich, Jansen \& Cole and Spink, Ozmutlu \& Lorence leave sexual arousal unexamined. Perhaps these studies affiliate the sensual and affective dimensions of pornography with imprecise humanistic criticism, in favor of more "rigorous" and "objective" (quantitative) modes of description.

The neglect to examine carnal responses in pornography may reflect an assumption that the experience of information is fundamentally cognitive -- á la Belkin's Anomalous States of Knowledge [18]. As such, our embodied experiences become immediately objectified, not only in the form of quantitative descriptions, but also in the form of self-conscious awareness or positive knowledge. The perception of pornography, however, cannot be reduced to a question of knowledge alone, just as sensation cannot be equated with the reflective consciousness of making sense. In other words, perception cannot reduce only to the senses, just as sensation does not wholly constitute conscious knowledge.

Perception (or "sense making") owes as much to embodied existence as it does to conscious thought. Following Brenda Dervin, information-seeking scholars commonly describe the way we perceive our world and others through our engagements with information as "sense-making" [19]. While Dervin cites phenomenological theorists, her sense-making model has little to say about embodied ways of knowing. By considering the senses, following Maurice Merleau-Ponty [20], I am offering a different account of sense making. To suggest that sense making is either embodied or conscious is to reproduce Cartesian dualism's mind/ body split. One should not make the mistake, however, of thinking that carnality and consciousness are equally valued in every sense-making situation; they are not fully disclosed to each other, and at times one might preoccupy us more than the other.

Sense making is neither purely conscious nor corporal; rather, it is mediated through both consciousness and corporality and, 
therefore, always indirect and incomplete. We cannot accomplish a holistic analysis of our experience of browsing online pornography through a methodology that attends only to conscious experience at the expense of embodied experience. Such is embodiment's centrality to this particular kind of browsing activity. An analysis of our engagements with and activity around online pornography must synthesize cognitive reflection and embodied experience.

\section{NEW MODES OF DESCRIPTION}

Existential phenomenology seeks such a synthesis. Because I am concerned with the decidedly material nature of human existence, specifically our embodied encounters with and activity around online pornography, I have adopted a method of critical practice guided by existential phenomenology. Ihde [21] characterizes this method as "a philosophical style that emphasizes a certain interpretation of human experience, and that, in particular, concerns perception and bodily activity." Merleau-Ponty [22], the philosopher whose work on embodiment transformed transcendental phenomenology into existential phenomenology, explains that the purpose of this method is "to describe the animation of the human body, not in terms of the descent into it of pure consciousness or reflection, but as a metamorphosis of life and the body, as the "body of the spirit." Finally, Sobchack [23], in her study of film and embodiment, describes existential phenomenology as "philosophically grounded on the carnal, fleshy, objective foundations of subjective consciousness as it engages and is transformed by and in the world." Combining an analysis of bodily activity with the reflective process of writing and scholarship, existential phenomenology synthesizes both cognitive reflection and embodied experience.

Sobchack's emphasis on our bodies' engagement and transformation by and in the world reminds us that embodied experience is always already shaped by the context of history and culture. Embodiment does not take place apart from an historical and cultural existence. As such, embodiment cannot be reduced to fixed essences; instead, embodied experiences are always open to other interpretations. Existential phenomenology is, therefore, a subjective method that will help improve our understanding of the way our bodies, in addition to conscious, reflective thought, engage in certain browsing processes.

As such, this essay adheres, in certain ways, to Day's reconceptualization of subjects, objects, and their relations. Day [24] suggests an end to certain understandings "of human beings and their activities as either determinative causes of, or effects from, 'generating' or 'using' information." Like Day, my method inverts models of the mind (mechanism, cognitivism, and behaviorism) and displaces the concept of need into a contrasting conceptualization of subjectivity and objects. This essay also demonstrates one way in which our relations to objects (such as representations and technology) constitute us as subjects. An analysis of our encounters with and activity around information must, therefore, consider our subjective relations with information, including the value and meaning we derive from information activity. ${ }^{\text {ii }}$

Examining our embodied encounters with information and its technological apparatus does not adhere easily to behaviorist and scientific modes of description. Computer technologies and their attendant networks of communication (including televisual, audiovisual, cinematic, and photographic) are never merely used, never merely instrumental. As I shall show, they are part of our lives and help constitute our embodied existence in ways that are profoundly personal. It is, therefore, not an exaggeration to say that our encounters with the objective phenomena of computer technologies transform us as embodied subjects and alter our subjectivity.

Therefore, rather than rely on detached and dispassionate modes of description, this essay relies on a method and discourse that reflects our subjective experiences. For example, following Day, we are not "users" - a word that echoes the prevalent rhetoric of addiction that surrounds sex and the Internet. In popular discourse, addicts are "users". Some may argue that my use of the subjective case of the first person plural pronoun ("we" and its reflexive "our") is merely anecdotal or a rhetorical attempt to universalize subjective experiences. Others may wonder whether subjective experience can contribute to generalizable knowledge. Let me address these two points in turn.

Subjective analysis, particularly a focus on what it is to live one's body, is indeed at least partly anecdotal to the extent that it relies on lived experience. It is important to remember that embodiment is fundamentally part of what it is to be human (we are bodies; we do not have bodies). That is to say, embodiment, in addition to conscious, reflective thought, helps constitute our subjectivity. The purpose of analyzing the subjective (and sometimes personal) experience is not to universalize a particular experience. Neither should we confuse the process of subjectivity with individualism or particularity. As Braidotti [25] explains, "Subjectivity is a socially mediated process. Consequently, the emergence of new social subjects is always a collective enterprise, external to the self while it also mobilizes the self's in-depth structure." My turn to the subjective second person plural pronoun ("we") reflects the collective enterprise of subjectivity. Furthermore, the intention of my subjective analysis is to open up (rather than close down) our understanding of more general entailments of our engagements with and activity around online pornography and to suggest an intimate and material relationship we have with those engagements and activities.

A turn to the subjective is not merely a self-indulgent analysis of an individual encounter with online pornography. Its aim is to describe and explicate the general and possible structures that inform this particular browsing process and make it potentially resonant for others. Sobchack [26] puts it best in the following passage:

Although in historical and cultural existence
particular experiences may be lived
idiosyncratically, they are also, and in most cases,
lived both generally and conventionally - in the
first instance, according to general conditions of
embodied existence such as temporality,
spatiality, intentionality, reflection, and
reflexivity and, in the second instance, according
to usually transparent and dominant cultural
habits that are not so much determining as they
are regulative.

Much of this will come through in my analysis below, but I want to emphasize that the value of subjective experience is not necessarily whether I have actually had the experience (indeed, that is besides the point); it is about whether or not "the description is resonant and the experience's structure sufficiently comprehensible to a reader who might possibly inhabit it (even if in a differently inflected or values way)" [27]. Finally, to the 
extent that the experience of online pornography is embodied and intimate, subjective logic serves as an antidote to the behaviorist and scientific accounts of our experience of online pornography that do not describe our living that experience.

\section{THE ROLE OF DESIRE IN BROWSING ONLINE PORNOGRAPHY}

An analysis of our engagements with and activity around online pornography that relies on existential phenomenology should perhaps start with an explanation of how such activity constitutes "browsing" rather than "searching." Scholars predominantly use the latter term to describe activity around online pornography. Whereas "searching" implies a goal-oriented, purposeful activity, "browsing," according to Case [28], emphasizes accidental, incidental, or serendipitous encounters with information. Browsing has a close association with recent studies that concern leisurely and pleasurable information activities. In her study on the information activity of gourmet food cooking, Hartel [29] shows that browsing can characterize activity in which pleasure derives from the process of the "search" itself. Hartel's gourmet food hobbyists do not necessarily identify in advance an exact recipe they want, nor do they necessarily favor the easiest path to finding it. Instead, the activity reveals a pleasure in serendipitous discovery. Because not just any recipe will do, the hobbyists in Hartel's study derive pleasure from the hard-to-find object. In some ways, the same activity might characterize a stamp collector or bibliophile. Case [30] has similarly characterized the activity of coin collecting. Such activity is not analogous to, say, searching online for the cheapest and most convenient plane tickets - in which pleasure derives from finding a precise object, specified in advance, using the least amount of time and effort. Briefly, it is important to note that some forms of serial collecting involve identifying in advance precisely what one desires, such as searching for a particular coin. Even as we may serendipitously discover new objects in the process of finding a particular object, thereby conjoining and complicating the distinction between browsing and searching, this kind of information activity vacillates between being object-oriented (sometimes called purposeful or goal-oriented) and non-object-oriented.

By showing that we expend significant effort in our pleasurable browsing activities, Hartel and Case undercut the use to which some scholars have put Zipf's notion of the economy of effort (or the Principle of Least Effort) to explain the way we search for information and engage with information systems [31]. Such an explanation assumes that the effort of information activity is always unpleasant and that displeasure increases with the duration of that effort. Hartel and Case also undercut the assertion made by Choo that goal-oriented or purposeful searching requires greater effort than browsing [32]. As a result of these findings, Kari and Hartel [33] have called for a more concerted research effort in understanding pleasurable information activity, importantly, "from a subjective point of view."

Hartel's characterization of pleasurable browsing in some ways echoes that of online pornography. Yet our relations to representations of sexual desire and the illusive goal of browsing pornography complicate our understanding of pleasurable browsing in important ways. The process of browsing pornography online exists under the aegis of getting what we want, but in excess of it. Floods of images and an enormous range of selection seem to promise satisfaction. Online pornography is a prime example of information overload. To the extent that browsing online pornography is at all pleasurable, we might assume that it is also enjoyable and satisfying, following Kari \& Hartel [34] and Seligman \& Csikszentmihalyi's [35] definitions of pleasurable. In this way, browsing pornography has a discernable, albeit ostensible, goal or objective: sexual satisfaction. The aegis of such a goal in part allows us rationalize the pleasure of browsing. To imagine the goal is to project into a moment of perfect satisfaction: obtaining the perfect image, one completely adequate to our desire.

However, nothing can compare to an imagined perfect image, not just any image will do, and so the browsing experience continues. Following Jacque Lacan, Salvoj Žižek has succinctly articulated the impossibility of fulfilling one's desire: “desire's raison d'etre is not to rationalize its goal, to find full satisfaction, but to reproduce itself as desire" [36]. Thus, satisfaction is illusive. The nearly perfect image still only provides momentary satisfaction. In some instances, momentarily satisfied or frustrated, we walk away from the computer, only to return to it again at a later point because of the recursive nature of sexual desire. In other instances, even if we know we are unlikely to find a better image, we will continue to browse, forgoing the pleasures of the known for the pleasures of the unknown. We constantly shift to new images, creating a process of browsing in which pleasure derives from the habitual and repetitious delay and deferral of satisfaction. Derrida describes this process of delay and deferral as arrivant, the active form of the French verb arriver, which means to arrive at a goal or fulfill an intention [37]. Arrivant, thus, describes the process of arriving at a goal or objective without ever attaining it. We might also describe this nonteleological phenomenon as the sensation of being in duration.

Indeed, the process of browsing online pornography is one marked by the embodied experience of waiting. While the Internet promises immediate gratification, the interface of online pornography necessitate delays: logging on, finding a site, scrolling up and down/ left and right, opening and closing windows, clicking forward/ backward, and pushing the refresh button. Delays also arise from the material limitations of the technological apparatus of the computer, such as the capacity of silicon to conduct electrons at particular speeds, which results in the delay of waiting for a selected image, series of images, or moving image to appear. A high speed Internet may decrease this delay, but, according to Patterson, "cyberporn constantly pushes the boundaries of bandwidth; as soon as the technology can immediately deliver full-frame images, streaming video comes on offer, with slower load times. Even with a high-speed connection, there is still often delay on the side of the site delivering content" [38]. Waiting and looking become habit, thereby "inscribing repetition and delay as pleasures of a different order" [39]. At some point, there is a limit to the amount of waiting we will endure before our browsing experience becomes frustrating, but until that threshold, delay intensifies the pleasure of eventual visibility, amassed by the illusoriness of the perfect image.

Part of our frustration and delay may also owe to the labyrinthine design quality of some pornography websites. Websites with this method of design provide an overflow of images and moving images, arranged in a rambling and chaotic fashion, opposed to concepts of ordering and system. Think especially of pop-ups, advertisements, and flash and animated GIFs, not to mention sites with background music. Such a concept of design participates in delivering an excess and overflow. In this way, the design of some pornography websites seems to promise the accessible and 
visible while delivering the curious and obscure. ${ }^{\text {iii }}$ Pornography websites engage us visually, seductively, and affectively, revealing a corporal relation between display and viewer. Scholars of Enlightenment visual culture have similarly shown a corporal relation between exhibition and viewer in the arrangement of objects on display in the Baroque curiosity cabinet. This is not to say that the arrangement of pornographic images online today can be anchored solely in the referents of the early modern period, or that there is some kind of causal effect of old media on new. Instead, the digital functions as part of a baroque genealogy, which articulated differential relations between embodiment and technics. It places, according to Munster [40], "body and machine, sensation and concept, nature and artifice in ongoing relations of discordance and concordance with each other." "iv The arrangement of pornographic images online and the navigation it entails similarly serve an affective experience. Pornography websites' method of display is an aesthetic contrivance that solicits us sensually, drawing wonder, curiosity, surprise, disgust, irritation, and frustration from the viewer. As with the embodied experience of delay, the arrangement of images on display reveals the ways in which we experience both pleasure and frustration in the process of browsing pornography online.

Sigmund Freud most famously described the association of frustration and pleasure in his theory of cathexis. According to Freud [41], the psychic energy found in the id, which is responsible for satisfying basic desires, invests itself in an object, idea, or person in order to satisfy that desire, as in the case of sexual imagery. Freud represents frustration in libidinal desires as a blockage of psychic energy passing through the id. If sexual representation is a form of object-cathexis, then viewers browsing pornography experience libidinal frustration in the delay and deferral of sexual satisfaction. Freud's cathexis may begin to explain why Spink, Ozmutlu, and Lorence found that browsing online pornography requires more time and effort than other forms of Internet "searching." It is perhaps, at least partly, the nature of desire itself that accounts for such time and effort: desire is recursive, it involves delay and deferral, and its satisfaction is illusive.

\section{CONCLUSION}

Why might browsing pornography require more time and effort than other forms of web activity? The answer has to do with the nature of sexual desire and our embodied relations with technics. That desire is recursive, involves delay and deferral, and that its goal is illusive at least partly explains the time and effort we put into browsing representations of it.

Due to the limitations of space, this essay has said nothing about the role of embodiment in sexual sociability online. Indeed, browsing online pornography is a social experience. "There are literally hundreds of thousands of sites that cater to every masturbatory fantasy imaginable," writes Laqueur [42] "but what is really new is the proliferation of virtual communities of onanaists, an alternative universe of sociability that is created through the public revelation of the not-so-vice." Laqueur suggests that these online communities of masturbators constitute a change in the history of masturbation. Once a solitary sexual pleasure, marked by privacy, loneliness, self-absorption, guilt and shame, masturbation has come to be an increasingly public, social, and communal experience online. Some of the evidence for this may come from the incorporation of social networking design elements into pornography websites. Other evidence comes from the way in which we browse, organize, and retrieve online pornography through folksonomic forms of classification (tags) that allow for effective retrieval systems. Algorithms mediate some of these relations, recommending images or moving images that others found interesting, similar to Amazon.com ("customers who bought this item also bought"). The social aspects of browsing online pornography merit further attention.

Finally, while this essay demonstrates the importance of embodiment to understanding the process of browsing online pornography, I want to suggest that a focus on embodiment may prove helpful for explicating ideas and principles within information-seeking studies more broadly. One can trace issues of embodiment within information-seeking literature at least as far back as Taylor's foundational essay, "The Process of Asking Questions" [43], in which he describes the need for information as "visceral." In recent years, a number of studies have reflected our visceral relations and activity around information. These issues can be found in information-seeking studies that discuss embodiment (sometimes implicitly, sometimes explicitly) on a variety of registers: anxiety, leisure, pleasure, boredom, frustration, uncertainty, curiosity, serendipity, surprise, anticipation, immersion, sense-making or cognition, habits, and memory, not to mention desire. Each of these embodied topics is a major area of interest within information-seeking scholarship. Embodiment abounds within information-seeking research so much so that it perhaps serves as a point of convergence for (if not fundamental part of) many of the broader issues and debates within the field. Embodiment also gives us a new vantage point from which to study our activity around information. Traditionally, studies within information-seeking research have been arranged around particular information channels (library, archive, television, Internet, etc.) or people (consumers, students, scientists, lawyers, ethnic groups, etc.). Such an arrangement can lend itself to knowledge silos or over-simplification, unhelpful for explicating and making connections between ideas and principles. A focus on embodiment partly avoids those potential pitfalls by shifting our attention to themes rather than entities.

\section{ACKNOWLEDGMENTS}

Thanks to Julie Anderson, Joseph Bristow, Lois Cucullu, Johanna Drucker, Dustin Friedman, Jonathan Furner, Neil Hultgren, Gregory Leazer, and Jim Schultz for their contributions and their unfailingly sharp, clear, and useful critical comments.

\section{REFERENCES}

[1] Spink, A.; Ozmutlu, H. C.; and Lorence, D. P. (2004). Web searching for sexual information: An exploratory study. Information Processing \& Management 40(1), 113-124

[2] Cronin, B. \& Davenport, E. (2001). E-Rogenous zones: Positioning pornography in the digital economy. The Information Society 17(1), 33-48

[3] Spink, A.; Ozmutlu, H. C.; and Lorence, D. P. (2004). Web searching for sexual information: An exploratory study. Information Processing \& Management 40(1), p. 21

[4] Kari, J. \& Hartel, J. (2007). Information and higher things in life: Addressing the pleasurable and profound in information science. Journal of the American Society for Information Science and Technology 58(8), 1131-1142.

[5] Dworkin, A. (1989). Pornography: Men possessing women. New York: E. P. Dutton. 
[6] McKinnon, C. A. (1992). Pornography, civil rights and speech. In C. Itzin (Ed.), Pornography: Women, violence, and civil liberties. Oxford: Oxford University Press.

[7] Russell, D. (2000). Pornography and Rape: A Causal Model. In. D. Cornell (Ed.), Feminism and pornography. Oxford: Oxford University Press.

[8] Cornell, D. (2000). Feminism and pornography. Oxford: Oxford University Press.

[9] Williams, L. (2008). Screening sex. Durham, NC: Duke University Press.

[10] Kipnis, L. (1999). Bound and gagged: Pornography and the politics of fantasy in America. Durham, NC: Duke University Press.

[11] Spink, A.; Koricich, A.; Jansen, B. J.; and Cole, C. (2004). Sexual information seeking on web search engines. CyperPsychology \& Behavior 7(1), 65-72

Spink, A.; Ozmutlu, H. C.; and Lorence, D. P. (2004). Web searching for sexual information: An exploratory study. Information Processing \& Management 40(1), 113-124.

[12] Spink, A.; Koricich, A.; Jansen, B. J.; and Cole, C. (2004). Sexual information seeking on web search engines. CyperPsychology \& Behavior 7(1), p. 65

[13] Ibid.

[14] Ibid.

[15] Ibid., p. 71

[16] Dennett, D. (1995). Darwin's dangerous idea: Evolution and the meaning of life. New York: Simon and Schuster.

[17] Spink, A.; Koricich, A.; Jansen, B. J.; and Cole, C. (2004). Sexual information seeking on web search engines. CyperPsychology \& Behavior 7(1), p. 65

[18] Belkin, N. J. (1980). Anomalous states of knowledge as the basis for information retrieval. The Canadian Journal of Information Science 5, 133-143

Belkin, N. J.; Oddy, R. \& Brooks, H. (1982). ASK for information retrieval. Journal of Documentation 38, 61-71 (part 1) \& 145-164 (part 2).

[19] Dervin, B. (1992). From the mind's eye of the user: The sense-making qualitative-quantitative methodology. In J. Glazier and R. Powell (Eds.). Qualitative Research in Information Management (pp. 61-84). Englewood, CO: Libraries Unlimited

Dervin, B. \& Foreman-Wernet, L., eds. (2003). Sensemaking methodology reader: Select writings of Brenda Dervin. Creskill, NJ: Hampton Press.

[20] Merleau-Ponty, M. (1964a). Signs. R. C. McCleary (Trans.). Evanston, IL: Northwestern University Press. . (1964b). The primacy of perception, and other essays on phenomenological psychology, the philosophy of art, history and politics. Evanston, IL: Northwestern University Press.

. (1970). Themes from the lectures at the Collège de France, 1952-1960. J. O’Neill (Trans.). Evanston, IL: Northwestern University Press.

. (1988). In praise of philosophy and other essays. $\mathrm{J}$

Wild \& J. M. Edie (Trans.). Evanston, IL: Northwestern University Press.
. (2005). Phenomenology of perception. C. Smith (Trans.). New York: Routledge. (2008). The world of perception. O. Davis (Trans.). New York: Routledge.

[21] Ihde, D. (1990). Technology and the life world: From garden to earth. Bloomington, IN: Indiana University Press.

[22] Merleau-Ponty, M. (1988). In praise of philosophy and other essays. J Wild \& J. M. Edie (Trans.). Evanston, IL: Northwestern University Press, p. 196.

[23] Sobchack, V. (2004). Carnal thoughts: Embodiment and moving image culture. Berkeley: University of California Press, p. 5.

[24] Day, R. (2011). Death of the user: Reconceptualizing sbjects, objects, and their relations. Journal of the American Society for Information Science and Technology 62(1), p. 78

[25] Braidotti, R. (2002). Metamorphoses: Towards a materialist theory of becoming. Malden, MA: Blackwell/ Polity Press, p. 7.

[26] Sobchack, V. (2004). Carnal thoughts: Embodiment and moving image culture. Berkeley: University of California Press, p. 1.

[27] Ibid.

[28] Case, D. (2007). Looking for information: A survey of research in information seeking, needs, and behavior. New York: Elsevier, p. 329.

[29] Hartel, J. (2007). Information activities, resources, and spaces in the hobby of gourmet cooking. Dissertation, University of California, Los Angeles.

[30] Case, D. (2009). Serial collection as leisure, and coin collection in particular. Library Trends 57(4), 729-752

[31] Zipf, G. K. (1949). Human Behavior and the Principle of Least Effort: An Introduction to Human Ecology, Cambridge, MA: Addison-Wesley. See also Case, D. O. (2007). Looking for information: A survey of research in information seeking, needs, and behavior. New York: Elsevier, p. 151-154

[32] Choo, C. W. (2001). Environmental scanning as information seeking and organizational learning. Information Research 17(1). Retrieved August 22, 2011 from http://informationr.net/ir/7-1/paper112.html.

Choo, C. W. (2001). Information management for intelligent organization: The art of scanning the environment. Medford, NJ: Information Today.

[33] Kari, J. \& Hartel, J. (2007). Information and higher things in life: Addressing the pleasurable and profound in information science. Journal of the American Society for Information Science and Technology 58(8), 1133

[34] Ibid.

[35] Seligman, M. E. P. and Csikszentmihalyi, M. (2000). Positive psychology: An introduction. American Psychologist 55(1), 5-14.

[36] Lacan, Jaques. (1992). The Seminar of Jacques Lacan, Book VII: The Ethics of Psychoanalysis. Trans. Dennis Porter. New York: W. W. Norton. . (2007). Ecrits. Trans. Bruce Fink. New York: W. W. Norton. 
Žižek, Slavoj. (1997).The Plague of Fantasies. New York: Verso, p. 39

[37] Derrida, J. (1993). Aporias. T. Dutoit (Trans.). Stanford: Stanford University Press, p. 34

[38] Patterson, Z. (2004). Going on-line: Consuming pornography in the digital era. In L. Williams (Ed.), Porn Studies (p. 109). Durham, NC: Duke University Press.

[39] Ibid.

[40] Munster, A. (2006). Materializing new media: Embodiment and information aesthetics. Hanover, NH: Dartmouth College Press, p. 5

[41] Freud, S. (1990). The ego and the id. New York: W. W. Norton.

[42] Laqueur, T. (2003). Solitary Sex: A Cultural History of Masturbation. New York: Zone, p. 419.
[43] Taylor, R. (1962). The process of asking questions. Journal of the American Society for Information Science 13, p. 392.

[44] Chauncy, G. (1991). Christian brotherhood or sexual perversion? Homosexual identities and the construction of sexual boundaries in the World War I Era. In M. B. Duberman, et al. (Eds.) Hidden from history: Reclaiming the gay and lesbian past (pp. 294-317). New York: Penguin.

[45] Munster, A. (2006). Materializing new media: Embodiment and information aesthetics. Hanover, NH: Dartmouth College Press.

[46] Murray, T. (2008). Digital baroque: New media art and cinematic folds. Minneapolis, MN: University of Minnesota Press.

\section{END NOTES}

${ }^{i}$ At times, Spink, Ozmutlu \& Lorence obfuscate the extent to which pornography gets subsumed under a broader rubric of "sexual information" that includes health resources. Health resources and pornography are markedly different in both their representational content and the activity around them. Spink, Koricich, Jansen \& Cole, on the other hand, imbricate pornography with chat room discussions. The differences between these different modes of sexual communication and representation deserve a clearer distinction.

${ }^{\text {ii }}$ Day takes great pains to explain his philosophical method and to provide, where relevant within the limited space of a journal article, the intellectual history that allows for his various mappings and remappings of ontological concepts about subject-object relations.

iii Even if pornography websites contain classification schemas to make information retrieval effective through keyword searches, the choice of categories of fetishes is regulatory productive. The classification functions to guide, if not overtly discipline, our subject positions and desires by creating an environment in which subjects and desires are produced as essential standards. Folksonomic classifications, such as tags, reflect a complicated relationship with the dominant culture. While the bounds of power are not always topdown, folksonmic classification is not free of discipline. On this point, see especially Chauncey [44]. While we might role-play within these classifications, the exploration is constrained by a logic of recognizable cues, yet made obscure by the lack of transparency of language, in which a keyword returns false hits, further attributing to the labyrinthine design quality of certain pornography websites.

iv That digital visual culture is part of a Baroque genealogy has been articulated by numerous scholars, most notably Munster [45] and Murray [46]. 